\title{
Accruals and Value/Glamour Anomalies: The Same or Related Phenomena?
}

\author{
Gary Taylor \\ Culverhouse School of Accountancy, University of Alabama, Tuscaloosa \\ AL 35487, USA
}

Tel: 1-205-348-4658Ｅ-mail: gtaylor@cba.ua.edu

Randall Zhaohui $\mathrm{Xu}$ (Corresponding author)

Accounting Department, University of Houston-Clear Lake

2700 Bay Area Blvd., Box 42, Houston, TX 77058, USA

Tel: 1-281-283-3145 E-mail: xuzhao@uhcl.edu

Received: March 31, $2011 \quad$ Accepted: April 18, $2011 \quad$ doi:10.5539/ijbm.v6n9p14

\begin{abstract}
We apply the set theory to investigate the patterns of market returns associated with three market anomalies to explore their relationships: (1) the accruals anomaly (ACC), and (2) two manifestations of the value/glamour anomaly: the cash flows-to-price (CFOP) and the book-to-market anomalies (BM). The purpose is to determine whether these are truly unique anomalies caused by different factors or whether they are manifestations of the same underlying phenomenon. The results suggest that although the accruals anomaly shares some factors with the CFOP and BM anomalies, the accruals anomaly has characteristics unique and separate from the two value/glamour anomalies.
\end{abstract}

Keywords: Accruals anomaly, Value/glamour anomalies, Incremental portfolio returns, Combined portfolio returns

\section{Introduction}

We investigate the market returns associated with three market anomalies: (1) the accruals (ACC) anomaly, and (2) two manifestations of the value/glamour anomaly: the cash-flows-to-price (CFOP) and the book-to-market (BM) anomalies. By examining the market returns generated from these three anomalies, we investigate whether the ACC and value/glamour anomalies are unique anomalies or just a function of the same anomaly generated from different fundamentals. The findings of this study enhance our knowledge on whether these anomalies, facilitating future research on the factors that creates the anomaly.

Desai, Rajgopal, and Venkatchalam (2004) investigate the relation between the ACC and CFOP anomalies. They compare ACC with CFOP to determine whether ACC has incremental association with future returns after controlling for CFOP. Desai, Rajgopal, and Venkatchalam (2004) find that investing strategies relying on ACC no longer produce significant abnormal returns after controlling for CFOP and infer that the ACC anomaly is actually a manifestation of the value/glamour anomaly. However, previous studies (Barth and Hutton, 2003; Collins and Hribar, 2000) suggest that in order to infer whether two anomalies are driven by the same underlying factors, one must estimate both the incremental and the combined return predictive power of the two anomalies. It is not feasible to determine the relationships between two market anomalies by looking solely at whether one has incremental return predictive power over the other. Both the incremental and combined returns need to be estimated.

This study adopts the methodology based on set theory as suggested in prior studies (Barth and Hutton, 2003; Collins and Hribar, 2000) to investigate whether the ACC is the same phenomenon as the value/glamour anomaly. We find that although the ACC anomaly shares some common factors with the BM and CFOP anomalies, it differs substantially from these two anomalies. These findings suggest that the ACC anomaly is essentially a different phenomenon from the value/glamour anomaly.

These results contribute to the market anomaly research. First, it extends Desai, Rajgopal, and Venkatchalam (2004). This study examines the combined return predictive power of the ACC and CFOP anomalies in addition to their comparative return predictive power. Furthermore, while Desai, Rajgopal, and Venkatchalam (2004) 
conduct their tests using only 12-month ahead portfolio returns, this study examines the 12, 24 and 36-month ahead portfolio returns. Since the mispricing reversion process may last several years (Lakonishok, Shleifer, and Vishny, 1994; La Porta, Lakonishok, Shleifer, and Vishny 1997), tests based on multi-year future returns would be expected to examine more aspects of the issue than tests based on only one-year ahead returns. Second, the higher abnormal returns generated by trading strategies using the combined return-predicting power of certain anomalies present a potentially profitable investment tool. The rest of the paper is organized as follows. Section 2 and 3 review relevant literature and discuss research methodology. The fourth and fifth sections describe test results and conduct supplemental analysis. The last part of the study discusses conclusions and implications.

\section{Literature Review}

Market anomalies refer to situations in which trading strategies earn abnormal returns based on current known information, such as the accruals and the book to market ratio. There is a significant body of literature that identifies market anomalies. Sloan (1996) shows that firms with low accruals earn positive future abnormal returns, while firms with high accruals earn negative abnormal returns. Fama and French (1993) and Lakonishok Shleifer, and Vishny (1994) document the positive association between the BM ratio and future stock returns. Desai, Rajgopal, and Venkatchalam (2004) document the positive association between the CFOP ratios and future stock return. The BM and CFOP anomalies are generally classified into the value/glamour anomaly. Value/glamour anomalies refer to the phenomenon well documented in finance literature that stocks with high ratios of fundamental measures of firm performance to price (value stocks), such as BM and CFOP ratios, earn higher returns than stocks with low ratios (glamour stocks).

Researchers have provided various explanations for the observed violations of market efficiency. Fama and French (1993 and 1998) argue that the abnormal returns for the investment strategies are compensation for risk, while other researchers (Kothari and Shanken, 1995; Kothari, Shanken, and Sloan, 1995; Kothari, Sabino, and Zach, 2005) suggest that the previously documented associations between some information variables and future returns may be caused by survivorship bias and data trimming. However, accounting and finance researchers have reported consistent and robust evidence that suggests that investors may not use all information efficiently in assessing firms' performance and future prospects. La Porta, Lakonishok, Shleifer, and Vishny (1997) document that the BM ratio have significant association with future returns even after controlling for various risk proxies and that a significant portion of the future returns occurs around subsequent earnings announcements.

As to how these apparent market anomalies could persist for such a long time even after they become well-documented, Ali, Hwang, and Trombley (2003) find that the BM effect is greater for stocks with higher idiosyncratic return volatility, higher transaction costs, and lower investor sophistication, suggesting a market-mispricing explanation for the anomaly. Their findings are consistent with the Shleifer and Vishny (1997) thesis that risk associated with the volatility of arbitrage returns deters arbitrage activity and is an important reason why the anomaly is not arbitraged away.

Prior research also examines the relations among the market anomalies. For example, Collins and Hribar (2000) and Barth and Hutton (2003) provide evidence that the accrual anomaly and the post-earnings announcement drift anomaly (analyst earnings revisions and the accrual anomaly) are different phenomena. Desai, Rajgopal, and Venkatchalam (2004) investigate the relation between the accruals anomaly and the cash flows anomaly and suggest that the accruals anomaly is a manifestation of the value/glamour anomaly.

\section{Methodology}

\subsection{Illustration of Relationships between Market Anomalies}

Utilizing set theory to motivate the discussion, the current study investigates relations between different market anomalies. This approach is illustrated in Figure 1. For discussion purposes, assume that there exists two market anomalies, A and B. Three types of relationships are diagrammed.

We define a Type I relationship as one in which the sets of factors associated with abnormal returns related to anomalies $\mathrm{A}$ and $\mathrm{B}$ are unique to each anomaly and each anomaly is regarded as a distinct phenomena. In terms of set theory, $A \cap B=\varnothing$ (the null set). An investment strategy that combines the set of factors of anomalies $\mathrm{A}$ and $\mathrm{B}$ is expected to generate higher abnormal returns (i.e. the combined returns) than those generated by a trading strategy utilizing the set of factors associated with A or B independently. However, controlling for the set of factors generating abnormal returns associated with anomaly B does not affect the abnormal returns generated from a trading strategy utilizing the set of factors associated with anomaly A, and vice versa (i.e. the incremental returns).

Under the Type II relationship, A and B are related to the similar set of factors. In other words, they are essentially different manifestations of the same underlying phenomenon. A may be roughly equal to B or much larger than B (Without losing generality, B can contain A. For simplicity, this case is not discussed here). In mathematical terms, either $B \approx A$ or $B \subset A$. A trading strategy that combines the sets of factors associated with A and $\mathrm{B}$ does not generate higher abnormal returns than a basic strategy based only on $\mathrm{A}$. On the other hand, the trading strategy utilizing the set of factors associated with $\mathrm{B}$ will not be able to generate significant abnormal returns after controlling for the set of factors associated with A. However, if the set of factors associated with A 
is significantly larger than the set of factors associated with B (i.e. $B \subset A$ and $A \succ(A \cap B)$ ), a strategy utilizing the set of factors associated with A may still produce significant abnormal returns after controlling for B.

The Type III relationship is one that lies between the Type I and Type II relationships. In this case, A and B share some common factors, but differs substantially from each other. The Type III relationship can be represented as $\{A \cap B \neq \varnothing$ and $A \succ(A \cap B)$ and $B \succ(A \cap B)\}$. A trading strategy that combines the sets of factors associated with $\mathrm{A}$ and $\mathrm{B}$ generates significantly higher abnormal returns than the returns generated by a trading strategy utilizing the set of factors associated with A or B independently. On the other hand, controlling for $A$ reduces the abnormal returns generated by the trading strategy based on $B$, and vice versa. One thing to note is that after controlling for B (A), the returns for the trading strategy based on A (B) may be significant or insignificant, depending on whether the subset of factors associated with $\mathrm{A}(\mathrm{B})$ above and beyond the common set of factors is substantial or not (i.e., whether the set of factors in $[A-(A \cap B)]$ or $[B-(A \cap B)]$ is material).

From the above discussions, it can be seen that it is not possible to differentiate among the three types of relationships only by examining the incremental abnormal returns. For example, Desai, Rajgopal, and Venkatchalam (2004) find that the strategy based on ACC did not produce significant abnormal returns after controlling for the power of CFOP. Their finding could reflect either a Type II or a Type III relationship between $\mathrm{ACC}$ and CFOP. Only by measuring both the incremental and the combined returns, one can determine whether the ACC and CFOP anomalies have a Type II relationship (i.e. the ACC and CFOP anomalies are different manifestations of the same underlying phenomenon) or Type III relationship (i.e. the two anomalies share some common factors, but differ significantly from each other).

\subsection{Research Methodology}

The relations between market anomalies are tested with portfolio hedge returns. The hedges used in market anomaly studies are basically zero-investment strategies that are implemented by short selling a portfolio of firms and using the proceeds of the short sales to invest simultaneously in another portfolio. Significant hedge returns reflect the return predictive power of the investment strategy. Following Lakonishok, Shleifer, and Vishny (1994), sample firms are grouped into quintile portfolios at the end of June each year based on the values of the accounting ratios: ACC, BM, and CFOP. Quartile 1 contains firms with the lowest values of the ratios, while quintile 5 contains firms with the highest values of the ratios. Three hedge strategies, including (1) the basic hedge, (2) the non-overlap hedge and (3) the combined hedge, are adopted to test the relations among the market anomalies. To control for potential differences in risk among the portfolios, size-adjusted buy-and-hold portfolio returns are used instead of raw returns. Following Sloan (1996), size-adjusted portfolio returns over the next 12, 24 and 36 months are calculated as the equal-weighted average of firm-specific size-adjusted returns. Firm-specific size-adjusted return is obtained by subtracting from a firm's buy-and-hold return the average return earned on a portfolio of firms with similar market capitalization. The size-matched portfolios are based on size deciles provided by CRSP.

The basic hedge is a simple strategy that utilizes the set of factors associated with one information variable. For example, to implement the basic hedge based on the CFOP ratio, firms are sorted into quintile portfolios according to values of CFOP in ascending order. Since prior studies find that firms with low (high) CFOP values tend to earn negative (positive) abnormal returns, the strategy is implemented by taking a short position in (i.e. short-sell) firms in the $1^{\text {st }}$ CFOP quintile, and a long position in (i.e. buy and hold) firms in the $5^{\text {th }}$ CFOP quintile.

The combined trading strategy combines the sets of factors associated with two information variables to estimate the combined abnormal returns for two anomalies. For example, to measure the combined abnormal returns of the ACC and CFOP anomalies, sample firms are sorted into quintiles according to ACC and CFOP, independently. Since prior studies find that firms with low (high) ACC tend to earn positive (negative) abnormal returns and that firms with low (high) CFOP tend to earn negative (positive) abnormal returns, the combined hedge strategy is implemented by taking a short position in firms that are simultaneously in the $5^{\text {th }}$ ACC quintile and the $1^{\text {st }}$ CFOP quintile, and a long position in firms that are simultaneously in the $1^{\text {st }}$ ACC quintile and the $5^{\text {th }}$ CFOP quintile.

The non-overlap hedge strategy assesses the incremental abnormal returns associated with one anomaly after controlling for the set of factors associated with another anomaly. For example, to test whether ACC produces any significant abnormal returns above and beyond that of CFOP, the nonoverlap hedge strategy is executed by taking a short position in firms that are in the $5^{\text {th }}$ ACC quintile but not simultaneously in the $1^{\text {st }} \mathrm{CFOP}$ quintile, and a long position in firms that are in the $1^{\text {st }}$ ACC quintile but not simultaneously in the $5^{\text {th }}$ CFOP quintile. The abnormal returns yielded by this strategy reflect the incremental returns of the ACC anomaly above and beyond the CFOP anomaly.

\section{Description of Data and Test Results}

\subsection{Sample Selection Criteria}

The study uses all US non-financial firms from 1978 to 2004, which meet the following data availability requirements: (1) have all the COMPUSTAT annual industrial file data items necessary to calculate the three ratios, i.e. ACC, BM, and CFOP; (2) have CRSP monthly returns for the 36 months after portfolio formation 
date on June 30 each year, stock prices and shares outstanding for end of June and December. The final year of the sample is 2004, because 36 months of CRSP stock returns following the portfolio creation are required to calculate portfolio returns. Firms that switch exchanges are traced to their new exchange listings and retained in their original portfolios. The proceeds, if any, from firms that drop out over the holding period are equally assigned to surviving firms in the same portfolio. Some firms have extremely low book values and/or earnings that would skew the distribution of the ratios. To eliminate these outliers, firms with negative book values of equity, ROEs with an absolute value higher than $100 \%$ and stock prices lower than $\$ 1$ are eliminated from the sample.

- ACC refers to firms' prior year accruals deflated by prior year total assets (COMPUSTAT data item 60). Accruals are measured using the balance sheet method as in Sloan (1996).

Accruals $=(\Delta \mathrm{CA}-\Delta \mathrm{Cash})-(\Delta \mathrm{CL}-\Delta \mathrm{STD}-\Delta \mathrm{TP})-\mathrm{Dep}$

Where $\triangle \mathrm{CA}$ is change in current assets (COMPUSTAT data item 4); $\Delta$ Cash is change in cash (COMPUSTAT data item 1); $\Delta \mathrm{CL}$ is change in current liabilities (COMPUSTAT data item 5); $\triangle \mathrm{STD}$ is change in debt included in current liabilities (COMPUSTAT data item 34); $\Delta \mathrm{TP}$ is change in income taxes payable; Dep refers to depreciation and amortization expenses (COMPUSTAT data item 14). In other words, the accruals defined here are actually changes in working capital minus depreciation and amortization expenses.

- As in Desai, Rajgopal, and Venkatchalam (2004), CFOP refers to firms' prior year cash flows from operations deflated by current year June 30 market value of equity from CRSP. Cash flows from operations are operating income after depreciation (COMPUSTAT data item 178) adjusted for the above-defined accruals.

- BM refers to firms' prior year book value of equity (COMPUSTAT data item 60) deflated by current year June 30 market value of equity from CRSP.

\subsection{Test Results}

The 12, 24 and 36-month size-adjusted returns for the basic hedges based on CFOP, BM, and ACC are listed in Table 1. The ACC strategy produces abnormal returns of $5.7 \%, 8.3 \%$ and $9.9 \%$ over the 12,24 and 36 -month periods, respectively. The CFOP strategy produces similar levels of hedge returns to the ACC strategy. Although the BM strategy fails to produce significant returns in the 12-month period, it generates significant abnormal returns of $8.8 \%$ and $13.3 \%$ over the 24 and 36 -month periods.

\section{Insert Table 1 about here}

Table 2 contains the test results on the relationships of the three anomalies. In Panel A, the 12, 24 and 36-month combined returns of ACC and CFOP are $9.0 \%, 13.0 \%$ and $18.0 \%$, which are significantly higher than the basic hedge returns of either ACC or CFOP. The 12, 24, and 36-month nonoverlap hedge returns for ACC (CFOP) are $2.0 \%, 3.4 \%$ and $1.9 \%(1.6 \%, 0.3 \%$ and $3.7 \%)$ respectively, which are significantly lower than the basic hedge returns of ACC (CFOP). The test results indicate that ACC has a Type III relationship with CFOP. In other words, although ACC has some similarity with the other three anomalies, it differs significantly from CFOP.

Panel B presents the test results on the relations between ACC and BM. The combined returns for ACC and BM are significantly higher than the basic hedge returns. The nonoverlap hedge returns for ACC and BM are all significantly lower than their basic hedge returns. The overall evidence suggests that, while the ACC anomaly has some common factors with the CFOP and BM anomalies, there are substantial differences between the ACC anomaly and the other anomalies. The results suggest a Type III relationship between the ACC anomaly and the $\mathrm{BM}$ and CFOP anomalies.

\section{Insert Table 2 about here}

\section{Sensitivity Analysis}

\subsection{Effect of Deflators on Hedge Returns}

ACC is deflated by total assets, while BM and CFOP are deflated by market price. It is reasonable to question whether the difference between the ACC anomaly and the other two anomalies is caused by the different deflators rather than by the information sets contained in these ratios. To test whether the relations between the ACC anomaly and the BM and CFOP anomalies are mainly driven by the deflators, ACC is replaced with ACCP, where ACCP is the ratio of total accruals divided by market value of equity. Consequently, ACCP has the same deflator as BM and CFOP. As shown in Panel A of Table 3, the 12, 24 and 36 month combined hedge returns of $\mathrm{ACCP}$ and $\mathrm{CFOP}$ is $8.9 \%, 11.8 \%$, and $16.9 \%$, respectively. The combined 24 and 36-month hedge returns are significantly higher than the basic hedge returns for either ACCP or CFOP. On the other hand, the 12, 24, and 36-month non-overlap returns for CFOP after removing for the effect of CFOP are $1.6 \%, 1.1 \%$ and $2.2 \%$ respectively, significantly lower than the basic hedge returns for CFOP. The 36 month return for CFOP after removing for the effect of ACCP are also significantly lower than the 36 month basic hedge return for CFOP. The pattern of the combined and non-overlap hedge returns for ACCP and CFOP indicates that ACCP differs substantially from CFOP, although there are some similarities between ACCP and CFOP. Test results in Panel B are similar to those in Panel A. Overall, ACCP demonstrates the same type of relationship with BM and CFOP as ACC. The results in Table 3 indicate that the relations between ACC and the BM and CFOP anomalies are not 
driven by the deflators.

\section{Insert Table 3 about here}

\subsection{Effect of Portfolio Size on Hedge Returns}

While the combined hedges of ACC with BM or CFOP produce higher returns than the basic trading strategies, there are fewer firms in the trading portfolios in the combined hedges than in the basic hedges. For example, the combined hedge of ACC and CFOP sells short a portfolio of 4561 firms with high ACC ratios and low CFOP ratios, and buy a portfolio of 3072 firms with low ACC ratios and high CFOP ratios. The basic hedges for ACC and for CFOP have about 7800 firms in each of the portfolios. Since smaller portfolios may consist of firms with more extreme values of ACC or CFOP ratios, it is unclear whether the higher combined returns are mainly due to the combined information sets of ACC and CFOP or due to the fewer numbers of firms in the combined hedge portfolios.

Thus, we construct basic hedge portfolios with the same numbers of firms as in the corresponding combined hedge portfolios and compare the combined hedge returns with the basic hedge returns obtained with matched size portfolios. In Panel A of Table 4, the combined hedge of ACC and CFOP sells short a portfolio of 4561 firms and buy a portfolio of 3072 firms. A corresponding basic hedge for ACC is constructed to sell short a portfolio of 4561 firms and buy a portfolio of 3,072 firms. This basic hedge for ACC with matched portfolio sizes generates 12,24 , and 36-month returns of $5.1 \%, 9.6 \%$, and $9.1 \%$, which are significantly lower than the combined hedge returns. Similarly, the basic hedge for CFOP with matched portfolio sizes produces 12, 24 and 36-month returns of $5.7 \%, 7.3 \%$, and $11.0 \%$, significantly lower than the combined hedge returns for ACC and CFOP. In Panel B, the combined hedges of ACC and BM also produce higher returns than the basic hedges with matched portfolio sizes in most cases. These findings suggest that the higher combined hedges returns are mainly produced by utilizing the richer information sets rather than by forming portfolios with fewer firms.

\section{Insert Table 4 about here}

\section{Conclusion}

This study investigates whether the ACC anomaly can be classified as the same type as the BM and CFOP anomalies. We find that although the ACC anomaly shares some common factors with the BM and CFOP anomalies, it differs significantly from these two value/glamour anomalies. This study does not test the specific source of market inefficiencies. This is a common limitation with studies on relationships between different market anomalies (Basu, 2004). Another limitation is that the size-adjusted returns used to proxy for abnormal returns may not fully adjust for the risk associated with the investment strategies and ignore transaction costs. However, since the study focuses on comparative magnitudes of the investment strategies and the potential bias with the measured investment returns is likely to be in the same direction for all strategies, the omission of transactions costs should not affect our conclusions about the relationships between the market anomalies.

\section{References}

Ali, A., Hwang, L., \& Trombley, M. (2003). Arbitrage risk and the book-to-market anomaly. Journal of Financial Economics, Vol. 69, 355-373. doi:10.1016/S0304-405X(03)00116-8, http://dx.doi.org/10.1016/S0304-405X(03)00116-8

Barth, M., \& Hutton, A. (2003). Analyst earnings forecast revisions and the pricing of accruals. Review of Accounting Studies, Vol. 9 No. 1, 59-96.

Basu, S. (2004). What do we learn from two new accounting-based stock market anomalies? Journal of Accounting and Economics, Vol. 38 No. 1, 333-348. doi:10.1016/j.jacceco.2004.10.001, http://dx.doi.org/10.1016/j.jacceco.2004.10.001

Collins, D., and Hribar, P. (2000). Earnings-based and accrual-based anomalies: one effect or two? Journal of Accounting and Economics, Vol. 29 No. 1, 101-123. doi:10.1016/S0165-4101(00)00015-X, http://dx.doi.org/10.1016/S0165-4101(00)00015-X

Desai, H, Rajgopal, S., \& Venkatchalam, M. (2004). Value-glamour and accruals mispricing: One anomaly or two? The Accounting Review, Vol. 79 No. 2, 355-385. doi:10.2308/accr.2004.79.2.355, http://dx.doi.org/10.2308/accr.2004.79.2.355

Fama, E., \& French, K. (1993). Common risk factors in the returns on stocks and bonds. Journal of Financial Economics, Vol. 33 No. 1, 3-56. doi:10.1016/0304-405X(93)90023-5, http://dx.doi.org/10.1016/0304-405X(93)90023-5

Fama, E., \& French, K. (1998). Market efficiency, long-term returns, and behavioral finance. Journal of Financial Economics, Vol 49, 283-306. doi:10.1016/S0304-405X(98)00026-9, http://dx.doi.org/10.1016/S0304-405X(98)00026-9

Kothari, S. P., \& Shanken, J. (1995). In defense of beta. Journal of Applied Corporate Finance, Vol. 8 No. 1, 53-59. doi:10.1111/j.1745-6622.1995.tb00273.x, http://dx.doi.org/10.1111/j.1745-6622.1995.tb00273.x 
Kothari, S. P., Shanken, J., \& Sloan, R. (1995). Another look at the cross-section of expected stock returns. Journal of Finance, Vol. 50, 185-224. doi:10.2307/2329243, http://dx.doi.org/10.2307/2329243

Kathari, S.P., Sabino, J., \& Zach, T. (2005). Implications of survival and data trimming for tests of market efficiency. Journal of Accounting and Economics, Vol 39, 129-161. doi:10.1016/j.jacceco.2004.02.003, http://dx.doi.org/10.1016/j.jacceco.2004.02.003

Lakonishok, J., Shleifer, A., \& Vishny, R. (1994). Contrarian investment, extrapolation, and risk. Journal of Finance, Vol. 49, No. 5, 1541-1578. doi:10.2307/2329262, http://dx.doi.org/10.2307/2329262

La Porta, R., Lakonishok, J., Shleifer, A., \& Vishny, R. (1997). Good news for value stocks: Further evidence on market efficiency. Journal of Finance, Vol. 52 No. 2, 859-874. doi:10.2307/2329502, http://dx.doi.org/10.2307/2329502

Shleifer, A., \& Vishny, R. (1997). The limits of arbitrage. Journal of Finance, Vol. 52, 35-46. doi:10.2307/2329555, http://dx.doi.org/10.2307/2329555

Sloan, R. (1996). Do stock prices fully reflect information in accruals and cash flows about future earnings? The Accounting Review, Vol. 71, No. 3, 289-326.

Table 1. Basic Hedge Portfolio Buy-Hold Returns Based on a Basic Strategy

\begin{tabular}{|c|c|c|c|c|c|c|}
\hline \multicolumn{7}{|c|}{ ACC QUINTILE } \\
\hline & Q1 & Q2 & Q3 & Q4 & Q5 & Q1-Q5 \\
\hline N Obs & 7802 & 7824 & 7815 & 7824 & 7808 & \\
\hline $\mathrm{ME}$ & 1771 & 2748 & 2636 & 1810 & 852 & \\
\hline $\mathrm{ACC}$ & -0.126 & -0.057 & -0.03 & 0.002 & 0.089 & \\
\hline SAR12 & 0.033 & 0.03 & 0.017 & 0.008 & -0.024 & $0.057 *$ \\
\hline SAR24 & 0.058 & 0.057 & 0.044 & 0.038 & -0.025 & $0.083^{* *}$ \\
\hline SAR36 & 0.077 & 0.081 & 0.058 & 0.053 & -0.022 & $0.099 * *$ \\
\hline \multicolumn{7}{|c|}{ BM QUINTILE } \\
\hline & Q1 & Q2 & Q3 & Q4 & Q5 & Q5-Q1 \\
\hline N Obs & 7802 & 7824 & 7815 & 7824 & 7808 & \\
\hline $\mathrm{ME}$ & 4115 & 2339 & 1468 & 1187 & 712 & \\
\hline $\mathrm{BM}$ & 0.201 & 0.376 & 0.548 & 0.761 & 3.55 & \\
\hline SAR12 & -0.007 & 0.011 & 0.013 & 0.014 & 0.034 & 0.042 \\
\hline SAR24 & -0.015 & 0.028 & 0.048 & 0.044 & 0.073 & $0.088^{*}$ \\
\hline SAR36 & -0.017 & 0.023 & 0.065 & 0.063 & 0.116 & $0.133^{* *}$ \\
\hline \multicolumn{7}{|c|}{ CFOP QUINTILE } \\
\hline & Q1 & Q2 & Q3 & Q4 & Q5 & Q5-Q1 \\
\hline N Obs & 7802 & 7824 & 7815 & 7824 & 7808 & \\
\hline $\mathrm{ME}$ & 965 & 2959 & 2571 & 1961 & 1359 & \\
\hline CFOP & -0.034 & 0.084 & 0.145 & 0.225 & 1.059 & \\
\hline SAR12 & -0.023 & -0.002 & 0.027 & 0.023 & 0.04 & $0.062 *$ \\
\hline SAR24 & -0.013 & 0.005 & 0.055 & 0.058 & 0.067 & $0.080 *$ \\
\hline SAR36 & -0.016 & 0.009 & 0.063 & 0.086 & 0.105 & $0.121 * *$ \\
\hline \multicolumn{7}{|c|}{$\begin{array}{l}\text { Variable Definitions: ACC refers to firms' prior year accruals deflated by prior year total } \\
\text { assets; BM refers to firms' book value of equity deflated by market value of equity; CFOP } \\
\text { refers to firms' prior year cash flows from operations deflated by current year June } 30 \text { market } \\
\text { value of equity from CRSP. * } * *, * * * \text { refer to significance at } 10,5 \text {, and } 1 \text { percent levels, } \\
\text { respectively. The statistical test is Wilcoxon signed rank non-parametric test. }\end{array}$} \\
\hline
\end{tabular}


Table 2. Tests on Relations of ACC with BM, CFOP, and VP Panel A: Tests on Relations between ACC and CFOP

\begin{tabular}{|c|c|c|c|c|}
\hline Return for combined hedge on ACC and CFOP: & N Obs & SAR12 & SAR24 & SAR36 \\
\hline Short-sell firms simultaneously in 5th ACC and 1st CFOP quintiles & 4561 & 0.045 & 0.049 & 0.048 \\
\hline Buy firms simultaneously in 1st ACC and 5th CFOP quintiles & 3072 & $\underline{0.047}$ & $\underline{0.084}$ & $\underline{0.132}$ \\
\hline Combined Return of ACC and CFOP & & $0.092 * *$ & $0.133 * *$ & $0.180 * * *$ \\
\hline Difference between combined hedge return and basic ACC hedge return & & 0.035 & $0.050 *$ & $0.081 * * *$ \\
\hline \multicolumn{2}{|l|}{ Difference between combined hedge return and basic CFOP hedge return } & 0.030 & $0.053 * *$ & $0.060 * *$ \\
\hline \multicolumn{5}{|l|}{ Return for nonoverlap hedge for ACC and CFOP } \\
\hline Short-sell firms in 5th ACC quintile but not simultaneously in 1st CFOP quintile & 3247 & -0.006 & -0.010 & -0.023 \\
\hline Buy firms in 1st ACC quintile but not simultaneously in 5th CFOP quintiles & 4730 & $\underline{0.026}$ & 0.044 & 0.042 \\
\hline Nonoverlap hedge returns for ACC & & 0.020 & $0.034^{*}$ & 0.019 \\
\hline \multicolumn{2}{|l|}{ Difference between nonoverlap hedge return and basic hedge return for ACC } & $-0.037 * *$ & $-0.049 * *$ & $-0.080 * * *$ \\
\hline Short-sell firms in 1st CFOP quintile but not simultaneously in 5th ACC quintile & 3241 & -0.017 & -0.049 & -0.044 \\
\hline Buy firms in 5th CFOP quintile but not simultaneously in 1st ACC quintile & 4736 & $\underline{0.032}$ & $\underline{0.052}$ & $\underline{0.080}$ \\
\hline Nonoverlap hedge returns for CFOP & & 0.016 & 0.003 & 0.037 \\
\hline \multicolumn{2}{|l|}{ Difference between nonoverlap hedge return and basic hedge return for CFOP } & $-0.046^{*}$ & $-0.077 * *$ & $-0.084 * *$ \\
\hline \multicolumn{5}{|l|}{ Panel B: Tests on Relations between ACC and BM } \\
\hline \multicolumn{5}{|l|}{ Return for combined hedge on ACC and BM: } \\
\hline Short-sell firms simultaneously in 5th ACC and 1st BM quintile & 2167 & 0.035 & 0.080 & 0.117 \\
\hline Buy firms simultaneously in 1st ACC and 5th BM quintile & 1827 & $\underline{0.051}$ & $\underline{0.094}$ & $\underline{0.143}$ \\
\hline Combined Return of ACC and BM & & $0.086 * * *$ & $0.174 * * *$ & $0.260 * * *$ \\
\hline Difference between combined hedge return and basic ACC hedge return & & 0.029 & $0.091 * * *$ & $0.161 * * *$ \\
\hline Difference between combined hedge return and basic BM hedge return & & $0.044 * *$ & $0.086^{* * *}$ & $0.127 * * *$ \\
\hline \multicolumn{5}{|l|}{ Return for nonoverlap hedge for ACC and BM } \\
\hline Short-sell firms in 5th ACC quintile but not simultaneously in 1st BM quintile & 5641 & 0.016 & -0.002 & -0.022 \\
\hline Buy firms in 1st ACC quintile but not simultaneously in 5th BM quintiles & 5975 & $\underline{0.026}$ & $\underline{0.045}$ & $\underline{0.052}$ \\
\hline Nonoverlap hedge returns for ACC & & $0.042 * *$ & $0.043 * *$ & $0.030 *$ \\
\hline \multicolumn{2}{|l|}{ Difference between nonoverlap hedge return and basic hedge return for ACC } & $-0.016^{*}$ & $-0.040 * * *$ & $-0.068 * * *$ \\
\hline Short-sell firms in 1st BM quintile but not simultaneously in 5th ACC quintile & 5635 & -0.005 & -0.012 & -0.026 \\
\hline Buy firms in 5th BM quintile but not simultaneously in 1st ACC quintile & 5981 & $\underline{0.027}$ & $\underline{0.063}$ & $\underline{\underline{0.104}}$ \\
\hline Nonoverlap hedge returns for BM & & 0.022 & $0.051 * *$ & $0.078 * *$ \\
\hline \multicolumn{2}{|l|}{ Difference between nonoverlap hedge return and basic hedge return for BM } & $-0.020 * *$ & $-0.037 * * *$ & $-0.055 * * *$ \\
\hline
\end{tabular}


Table 3. Tests on Relations of ACCP with BM and CFOP

\begin{tabular}{|c|c|c|c|c|}
\hline \multicolumn{5}{|l|}{ Panel A: Tests on Relations between ACCP and CFOP } \\
\hline Return for combined hedge on ACCP and CFOP: & N Obs & SAR12 & SAR24 & SAR36 \\
\hline Short-sell firms simultaneously in 5th ACCP and 1st CFOP quintiles & 4073 & 0.046 & 0.042 & 0.045 \\
\hline Buy firms simultaneously in 1 st $\mathrm{ACCP}$ and 5 th $\mathrm{CFOP}$ quintiles & 5398 & $\underline{0.043}$ & $\underline{0.077}$ & $\underline{0.124}$ \\
\hline Combined Return of ACCP and CFOP & & $0.089 * *$ & $0.118 * * *$ & $0.169 * * *$ \\
\hline \multicolumn{2}{|l|}{ Difference between combined hedge return and basic ACCP hedge return } & 0.027 & $0.029 *$ & $0.042 * *$ \\
\hline \multicolumn{2}{|l|}{ Difference between combined hedge return and basic CFOP hedge return } & 0.027 & $0.038^{*}$ & $0.048^{*}$ \\
\hline \multicolumn{5}{|l|}{ Return for nonoverlap hedge for ACCP and CFOP } \\
\hline $\begin{array}{l}\text { Short-sell firms in } 5 \text { th ACCP quintile but not simultaneously in 1st CFOP } \\
\text { quintile }\end{array}$ & 3735 & 0.003 & -0.016 & -0.035 \\
\hline Buy firms in 1 st ACCP quintile but not simultaneously in 5 th $\mathrm{CFOP}$ quintiles & 2404 & $\underline{0.026}$ & $\underline{0.067}$ & $\underline{0.086}$ \\
\hline Nonoverlap hedge returns for ACCP & & 0.029 & $0.051 * *$ & $0.051 * *$ \\
\hline \multicolumn{2}{|l|}{ Difference in nonoverlap hedge return and basic hedge return for ACCP } & -0.034 & $-0.038^{*}$ & $-0.076^{* * *}$ \\
\hline Short-sell firms in 1st CFOP quintile not simultaneously in 5th ACCP quintile & 3729 & -0.011 & -0.030 & -0.030 \\
\hline Buy firms in 5th CFOP quintile but not simultaneously in 1st ACCP quintile & 2410 & $\underline{0.028}$ & $\underline{0.041}$ & $\underline{0.052}$ \\
\hline Nonoverlap hedge returns for $\mathrm{CFOP}$ & & 0.016 & 0.011 & 0.022 \\
\hline \multicolumn{2}{|l|}{ Difference in nonoverlap hedge return and basic hedge return for CFOP } & $-0.046^{*}$ & $-0.069 * * *$ & $-0.099 * * *$ \\
\hline \multicolumn{5}{|l|}{ Panel B: Tests on Relations between ACCP and BM } \\
\hline \multicolumn{5}{|l|}{ Return for combined hedge on ACCP and BM: } \\
\hline Short-sell firms simultaneously in 5th ACCP and 1st CFOP quintile & 1361 & 0.062 & 0.110 & 0.162 \\
\hline Buy firms simultaneously in 1st ACCP and 5th CFOP quintile & 3772 & $\underline{0.050}$ & $\underline{0.090}$ & $\underline{0.143}$ \\
\hline Combined Return of ACCP and BM & & $0.112 * *$ & $0.200 * * *$ & $0.305 * * *$ \\
\hline \multicolumn{2}{|l|}{ Difference between combined hedge return and basic ACCP hedge return } & $0.049^{* *}$ & $0.111 * * *$ & $0.178 * * *$ \\
\hline \multicolumn{2}{|l|}{ Difference between combined hedge return and basic BM hedge return } & $0.070 * * *$ & $0.112 * * *$ & $0.172 * * *$ \\
\hline \multicolumn{5}{|l|}{ Return for nonoverlap hedge for ACCP and $\mathrm{BM}$} \\
\hline Short-sell firms in 5th ACCP quintile but not simultaneously in 1st BM quintile & 6447 & 0.018 & -0.008 & -0.026 \\
\hline Buy firms in 1st ACCP quintile but not simultaneously in 5th BM quintiles & 4030 & $\underline{0.021}$ & $\underline{0.057}$ & $\underline{0.089}$ \\
\hline Nonoverlap hedge returns for ACCP & & $0.039 *$ & $0.049 * *$ & $0.063 * *$ \\
\hline \multicolumn{2}{|l|}{ Difference in nonoverlap hedge return and basic hedge return for ACCP } & $-0.024 * * *$ & $-0.041 * * *$ & $-0.064 * * *$ \\
\hline Short-sell firms in 1st BM quintile but not simultaneously in 5th ACCP quintile & 6441 & -0.003 & -0.005 & -0.015 \\
\hline Buy firms in 5th BM quintile but not simultaneously in 1st ACCP quintile & 4036 & $\underline{0.016}$ & $\underline{0.054}$ & $\underline{0.091}$ \\
\hline Nonoverlap hedge returns for BM & & 0.014 & $0.049 *$ & $0.076^{* *}$ \\
\hline Difference in nonoverlap hedge return and basic hedge return for BM & & $-0.028 * * *$ & $-0.039 * * *$ & $-0.057 * * *$ \\
\hline
\end{tabular}

Variable Definitions: refer to Table 1. *,**,*** refer to significance at 10,5 , and 1 percent levels, respectively. 
Table 4. Comparison of Combined Hedge Returns with Basic Hedge Returns Using Matched Size Portfolios

\begin{tabular}{|c|c|c|c|c|}
\hline \multicolumn{5}{|l|}{ Panel A: Tests on Relations between ACC and CFOP } \\
\hline Return for combined hedge on ACC and CFOP: & N Obs & SAR12 & SAR24 & SAR36 \\
\hline Short-sell firms simultaneously in 5th ACC and 1st CFOP quintiles & 4561 & 0.045 & 0.049 & 0.048 \\
\hline Buy firms simultaneously in 1st ACC and 5th CFOP quintiles & 3072 & $\underline{0.047}$ & $\underline{0.084}$ & $\underline{0.132}$ \\
\hline Combined Return of ACC and CFOP & & $0.092 * *$ & $0.133 * * *$ & $0.180 * * *$ \\
\hline Returns for basic hedge based on ACC Using Matched Size Portfolios & & 0.051 & 0.096 & 0.091 \\
\hline Difference between combined hedge return and basic ACC hedge return & & 0.041 & $0.037 *$ & $0.090 * *$ \\
\hline Returns for basic hedge based on CFOP Using Matched Size Portfolios & & 0.057 & 0.073 & 0.110 \\
\hline \multicolumn{2}{|l|}{ Difference between combined hedge return and basic CFOP hedge return } & $0.035^{*}$ & $0.060^{* *}$ & $0.070 * *$ \\
\hline \multicolumn{5}{|l|}{ Panel B: Tests on Relations between ACC and BM } \\
\hline \multicolumn{5}{|l|}{ Return for combined hedge on ACC and BM: } \\
\hline Short-sell firms simultaneously in 5th ACC and 1st BM quintile & 2167 & 0.035 & 0.080 & 0.117 \\
\hline Buy firms simultaneously in 1 st $\mathrm{ACC}$ and 5 th BM quintile & 1827 & $\underline{0.051}$ & $\underline{0.094}$ & $\underline{0.143}$ \\
\hline Combined Return of ACC and BM & & $0.086^{* *}$ & $0.174 * * *$ & $0.260 * * *$ \\
\hline Returns for basic hedge based on ACC Using Matched Size Portfolios & & 0.039 & 0.079 & 0.096 \\
\hline Difference between combined hedge return and basic ACC hedge return & & 0.047 & $0.095^{* * *}$ & $0.164 * * *$ \\
\hline Returns for basic hedge based on BM Using Matched Size Portfolios & & 0.013 & 0.072 & 0.126 \\
\hline Difference between combined hedge return and basic BM hedge return & & $0.073 * * *$ & $0.102 * * *$ & $0.134 * * *$ \\
\hline
\end{tabular}

Type I---The Two Anomalies are Distinct Phenomena.
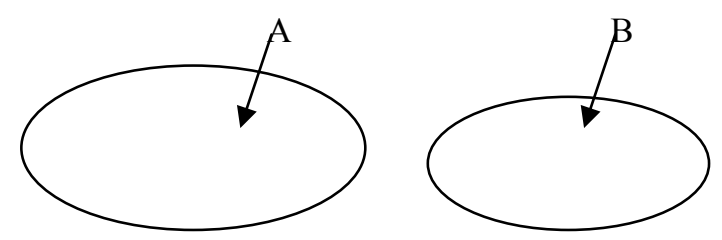

A and B have no common factors

Type II---The Two Anomalies are Different Manifestations of the Same Underlying Phenomenon.

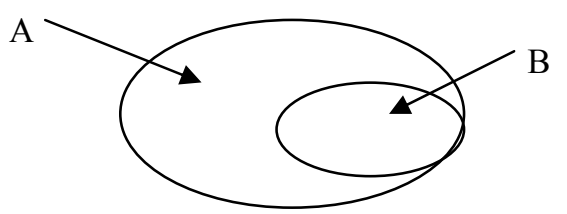

A contains $\mathrm{B}$, and is larger than $\mathrm{B}$

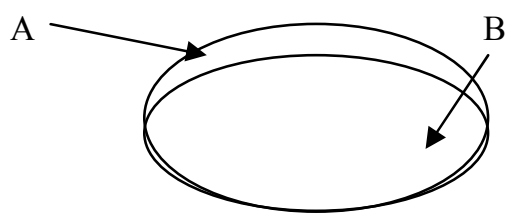

A contains $\mathrm{B}$, and is roughly equal to $\mathrm{B}$ 
Type III---The Two Anomalies Share Common Factors, but Differ Substantially.

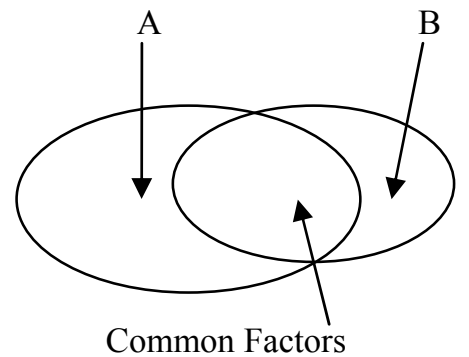

$\mathrm{A}$ and $\mathrm{B}$ share common factors. However, both A and B contain significant subset of factors above and beyond the common factors.

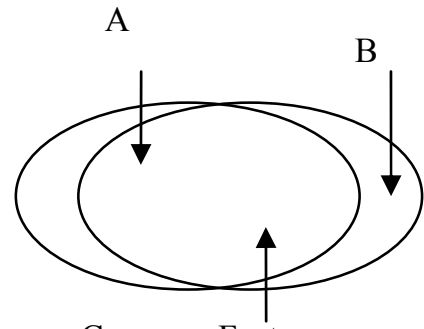

Common Factors

$\mathrm{A}$ and $\mathrm{B}$ share common factors. Neither A or B contains significant subset of factors above and beyond the common factors.
A

B

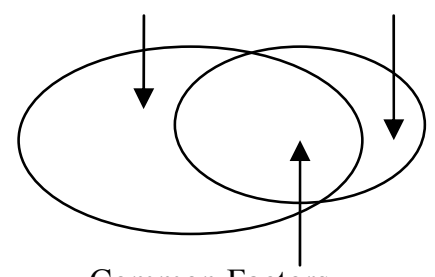

Common Factors

A and B share common factors. A contains a significant subset of factors above and beyond the common factors, but B does not.

Notes: The ellipses in the charts represent the sets of factors underlying the two market anomalies A and B that are associated with future returns.

Figure 1. Illustration of Types of Relationships between Market Anomalies 